\title{
AC 2011-1149: TEACHING THE GLOBAL, ECONOMIC, ENVIRONMEN- TAL, AND SOCIETAL FOUNDATIONS OF ENGINEERING DESIGN THROUGH PRODUCT ARCHAEOLOGY
}

\author{
Kemper Lewis, University at Buffalo - SUNY \\ Deborah A. Moore-Russo, University at Buffalo, SUNY \\ Omar M Ashour, Pennsylvania State University
}

$\mathrm{PhD}$ candidate in the Department of Industrial and Manufacturing Engineering at Pennsylvania State University. He received his MSc and BSc in Industrial Engineering from Jordan University of Science and Technology in 2007 and 2005, respectively. He received his MEng in industrial Engineering/Human Factors-Ergonomics from Pennsylvania State University in 2010. His research interests include decision making, health care engineering, and human factors. He is a member of IIE and JEA (Jordan Engineering Association).

Timothy W. Simpson, Pennsylvania State University, University Park

Professor of Mechanical \& Industrial Engineering

\section{Gul E. Okudan Kremer, Pennsylvania State University, University Park}

Gul Kremer is an Associate Professor of Engineering Design and Industrial Engineering at the Pennsylvania State University. She received her Ph.D. from University of Missouri-Rolla in Engineering Management and Systems Engineering. Her research interests include multi-criteria decision analysis methods applied to improvement of products and systems and enhancing creativity in engineering design settings. Her published work appears in journals such as Journal of Mechanical Design, Journal of Engineering Design, Journal of Intelligent Manufacturing, Journal of Engineering Education, European Journal of Engineering Education and Technovation. She is a member of IIE, ASME, and ASEE. She is also a National Research Council-US AFRL Summer Faculty Fellow for the Human Effectiveness Directorate (20022004), an invited participant of the National Academy of Engineering (NAE) Frontiers in Engineering Education Symposium (2009), and a Fulbright Scholar to Ireland (2010).

\section{Xaver Neumeyer, Northwestern University}

Ann F. McKenna, Arizona State University, Polytechnic campus

Ann McKenna is an Associate Professor in the Department of Engineering in the College of Technology and Innovation at Arizona State University (ASU). Prior to joining ASU she served as a program officer at the National Science Foundation in the Division of Undergraduate Education and was on the faculty of the Segal Design Institute and Department of Mechanical Engineering at Northwestern University. Dr. McKenna's research focuses on understanding the cognitive and social processes of design, design teaching and learning, the role of adaptive expertise in design and innovation, the impact and diffusion of education innovations, and teaching approaches of engineering faculty. Dr. McKenna received her B.S. and M.S. degrees in Mechanical Engineering from Drexel University and Ph.D. from the University of California at Berkeley.

Wei Chen, Northwestern University 


\title{
Teaching the Global, Economic, Environmental, and Societal Foundations of Engineering Design through Product Archaeology
}

\begin{abstract}
Many engineering departments often struggle with meeting "the broad education necessary to understand the impact of engineering solutions in a global, economic, environmental, and societal context" (Outcome h) that is required by ABET. The already packed curricula provide few opportunities to offer meaningful experiences to address this outcome, and most departments relegate this requirement to an early cornerstone or later capstone design experience as a result, making these courses an ineffective "catch all" for many ABET requirements. In this paper, we address this issue in a novel way by synthesizing concepts from archaeology with advances in cyber-enhanced product dissection to implement new educational innovations that integrate global, economic, environmental, and societal concerns into engineering design-related courses using product archaeology.
\end{abstract}

\section{Introduction and Motivation}

Outcome $\mathrm{h}$ in the requirements of ABET [1] has become a significant challenge to many engineering departments. Providing effective, useful, and engaging educational experiences to understand the global, economic, environmental, and societal impact of engineering solutions has proven to be a considerable task that entire teams of faculty are trying to address. Possible course approaches include early cornerstone design courses aimed at the freshmen and sophomore years, or later capstone design courses aimed at the junior or senior years. Another common response to provide a more global, socially sensitive context is to engage students in study abroad experiences. While the number of study abroad students historically was increasing, current economic conditions have impacted the ability for students and universities to fund such experiences. The challenge is therefore obvious - providing opportunities for students to experience global, social, economic, and environmental issues in engineering, with no funds to support the actual oversees travel.

We address this challenge in an innovative way using the product archaeology (PA) as the core curriculum paradigm. PA involves the process of reconstructing the lifecycle of a product - the customer requirements, design specifications, and manufacturing processes used to produce it to understand the decisions that led to its development. By considering products as designed artifacts with a history rooted in their development, we synthesize concepts from archaeology with advances in cyber-enhanced product dissection to implement new educational innovations that integrate global, economic, environmental, and societal concerns into engineering designrelated courses using product archaeology.

Talking about archaeology tends to conjure pictures of archeologists out in the field, digging in the dirt hoping to uncover artifacts that help them understand the life and times of the previous inhabitants. More specifically, "archaeologists try to reconstruct life and culture of past ages through the study of objects created by humans, known as artifacts" [2]. While archaeologists use a variety of tools and methods in their work, their approach to a new site can be generalized into four phases [3]: (1) preparation, (2) excavation, (3) evaluation, and (4) explanation. For instance, to prepare the site, archeologists might survey the site, take aerial photographs to assess the layout of the site, and research the history of the inhabitants. During the excavation phase, 
archaeologists may indeed spend time digging and explore the site, looking for artifacts, tools, clothes, art, and other relevant evidence of its previous inhabitants. Depending on the nature of the site, the evaluation phase can include methods for chronological analysis (e.g., carbon dating), or analyzing the social, environmental, and technological aspects of the site and its inhabitants. Based on the evidence that is obtained, archaeologists conclude the study by developing suitable theories to explain what transpired at the site drawing from a wide range of theories (e.g., migration, diffusion) and explanations [3].

If we consider consumer products as the artifacts under investigation, then we can create many useful pedagogical analogies with archaeology for engineering. We begin by defining product archaeology as the process of reconstructing the lifecycle of a product - the customer requirements, design specifications, and manufacturing processes used to produce it - to understand the decisions that led to its development. The concept of product archaeology is not new; it was first introduced by Ulrich and Pearson [4] as a way to measure the design attributes that drive cost through analysis of the physical products themselves. Our view is much broader in the sense that product archaeology provides an opportunity to study not only the manufacturing cost (i.e., economic issues) of a product, but also the global and societal context that influenced its development. It also provides a context for studying the environmental impact of a product by considering, for example, the energy and material usage throughout the life cycle of the product. When implemented in an engineering classroom, product archaeology allows students to place themselves in the minds of designers during the time a specific product was developed to try to re-create the global and local conditions that led to its development.

\section{Paradigm Development}

In order to further develop the archaeological analogy, we consider the four primary phases and their relevance in product design. The site preparation phase of archaeology corresponds to background research that an engineer would do before examining a product, including market research, patent searches, web searches, maybe even benchmarking existing products.

The excavation phase is analogous to product dissection whereby a product is disassembled, analyzed, and re-assembled to understand how it was made and how it functions [5]. While product archaeology represents a transformational advancement beyond product dissection, it builds upon and leverages the current widespread use of dissection activities in a number of diverse industrial and educational settings. For example, product dissection is an integral part of reverse engineering [6-7] and benchmarking [8-9], which are used by companies for competitive analysis (e.g., General Motors analyzes nearly 40 of its competitors' vehicles each year [10]) and design improvement (e.g., Whirlpool annually invites suppliers to disassemble and help improve Whirlpool products [11]). In the classroom, product dissection has become a popular pedagogy for engaging engineering students given its "hands-on" nature. Product dissection introduces students to functional products and processes, and providing such experiences early in the students' academic careers increases motivation and retention [12]. Product dissection can also be used to increase awareness of the design process [5], and such "learning by doing" activities encourage the development of curiosity, proficiency, and manual dexterity - three desirable traits of an engineer [13]. 
Many product dissection activities that are in use today have their roots in Professor Sherri Sheppard's Mechanical Dissection course at Stanford [14-15]. Numerous engineering courses $[11,13,16,21]$ have drawn upon the materials and activities developed for her course, which is now almost twenty years old. These initial developments were in response to a general agreement by U.S. industry, engineering societies, and the federal government that there had been a decline in the quality of undergraduate engineering education over the previous two decades [16-17]. As a result, there was a push towards providing both intellectual and physical activities (such as dissection) to anchor the knowledge and practice of engineering in the minds of students [18-19]. However, the majority of the product dissection activities that have resulted from these efforts tend to focus solely on the technological aspects of the product, namely, how it functions and how it is made. In fact, continuing the analogy to archaeology, most product dissection activities tend to emphasize the following during the evaluation and explanation phases:

- Function-form determinations: What function does each component perform? Why are they made of their particular material? What manufacturing processes were used to fabricate the component? How do the forms, material choices, and manufacturing processes of components work together to help fulfill their functions?

- Product architecture: Why was the final configuration and layout chosen? How are other related product configurations and platforms connected to this product?

While there are exceptions (e.g., dissection of single-use cameras as a means to discuss recycling and design for reuse [19]), many existing product dissection activities have missed opportunities to highlight the wide range of issues (e.g., global, economic, environmental, and societal) that influence product design and development.

Ironically, the factors influencing product development are in many ways the same ones that are impacting engineering education. Globalization, economic turmoil, environmental resource limitations, and interconnected social concerns are creating challenges that need engineers with a much broader perspective on their profession than they did even ten years ago. ABET has tried to address this in the "a-k outcomes" that are now part of EC 2000 [1]. However, as many departments undergo their second wave of accreditation reviews under the new criteria, many are still struggling with satisfying Outcome $h$. For instance, at Trinity College, a first-year design course is used to assess every ABET outcome except Outcomes h and i [20]. At Purdue, involvement in extracurricular activities were used to assess each of the ABET outcomes; however, the authors were not able to make any conclusions for Outcomes $h$, noting the need for "further analysis" of this outcome [21]. Breidis [22] noted that the assessment of Outcome h was "less straightforward" than the other professional outcomes, and a new course had to be developed to address this outcome directly. This strategy was used instead of the alternative of using the humanities and social science general education courses to assess Outcome $h$. However, most departments do not have the flexibility or room to develop a new course specifically to address any single ABET outcome, much less Outcome $h$. As a result, most departments relegate this requirement to their senior capstone design experience along with many other outcomes [23], and the end result is an ineffective "catch all" course with limited exposure to these increasingly important topics - too little, too late.

We assert that product archaeology can be used to create integrative learning materials that provide students with a more in-depth understanding of the global, economic, environmental, 
and societal issues that impact engineering solutions. Anchored in product dissection, these materials can be developed for a variety of engineering design-related courses that span freshmen through senior levels. The starting point for our work is discussed in the next section, which outlines the framework that we have developed for product archaeology instruction.

\section{Instructional Framework}

We have formalized a framework to classify archaeological activities based on the level of the students involved, shown in Figure 1. The framework utilizes two axes to indicate: (1) the amount of guidance provided by the instructor through either oral or written instructions, and (2) the students' required engineering knowledge, ranging from students being able to answer how questions (e.g., how does the device work?) to why questions (e.g., why did designers choose this material?) that can be answered through product archaeology activities. The Expose-InspireInquire-Explore quadrant lexicon is based upon the original product dissection-based framework presented in [5]. The level and type of activity for each quadrant are described as follows.

I. Expose - Best suited for 1st and 2nd year courses to familiarize students with products and artifacts in a structured way, to teach students engineering vocabulary and terminology, and to overcome any anxiety with engineering; must be highly structured to ensure proper progress through the activities.

II. Inspire - Useful in 1st and 2nd year courses to introduce design, graphics, or reinforce fundamentals from engineering courses such as statics and mechanics of materials; usually less structured to promote self-discovery.

III. Inquire - Primarily used in 3rd and 4th year courses to provide hands-on activities to reinforce engineering principles and theory; usually highly structured to ensure that the material is covered properly.

IV. Explore - Appropriate for 3rd and 4th year design courses to support idea generation, redesign, and benchmarking; application of 'core' engineering knowledge; or an integral part of a design process; usually requires the least amount of supervision - intended to foster selfdiscovery.

We have mapped the four phases of product archaeology onto this framework as a way to embody tangible strategies for providing opportunities for students to get exposed, get inspired, inquire, and explore.

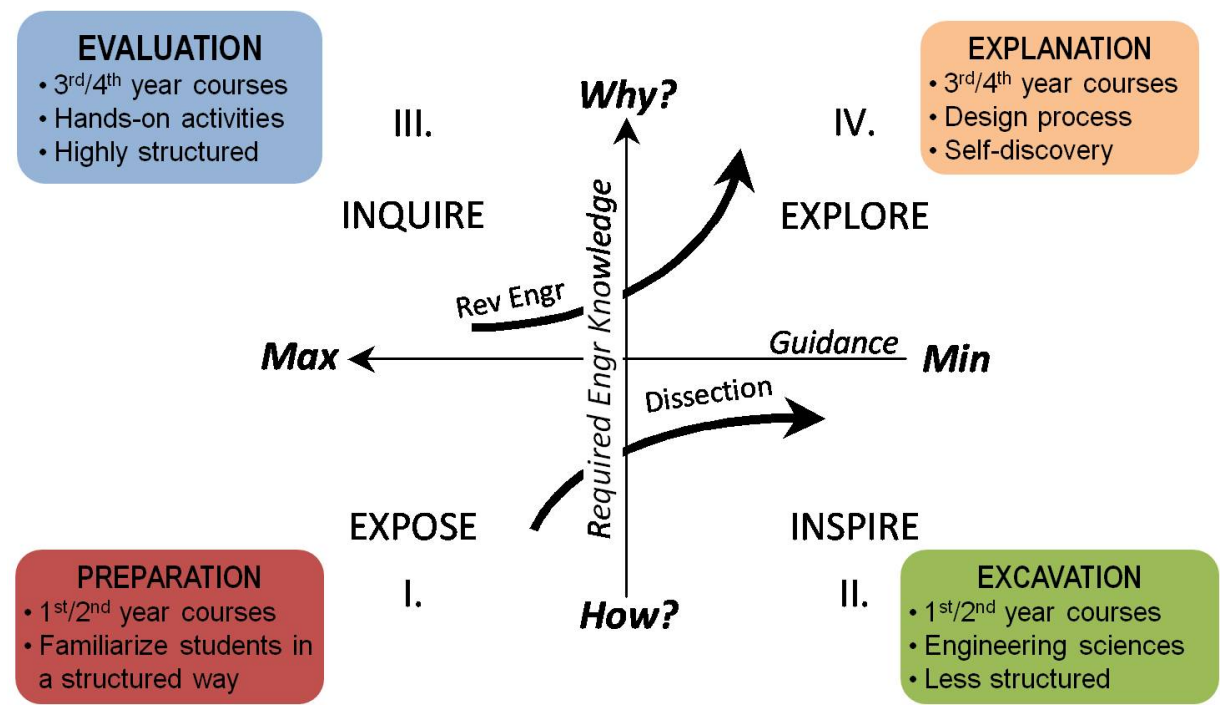

Figure 1. Product Archaeology Framework 
We have also integrated this framework with the Kolb model of experiential learning to guide future pedagogical developments based on more advanced product archaeology exercises. Kolb [24] argues that learning is a four-stage process involving the four learning modes of concrete experience, reflective observation, abstract conceptualization, and active experimentation. We propose that Kolb's four stages of learning can be mapped to the four phases of archaeological exploration as shown in Figure 2.

Specifically, during the preparation phase students will reflect on what they know about the factors that impact the design of particular products and postulate responses to several questions relating to economic, societal, etc. aspects of the designs. The excavation activities serve as concrete experiences where students can physically dissect products and perform appropriate research to develop well-reasoned answers to specific design-related questions. The evaluation and explanation phases provide opportunities for students to actively experiment and abstract meaning from both their research and concrete dissection experiences, reflecting on their work in the context of how global, economic, environmental and societal factors influence design decisions. Our approach to developing archaeological exercises embeds explicit opportunities for students to reflect on their experiences and, based on these reflections, abstract ideas about how components function and why they are made based on global, economic, environmental, and societal influences. In this way, our pedagogy and assessment mechanisms provide a holistic learning experience with equal emphasis on the four learning modes in Kolb's model.

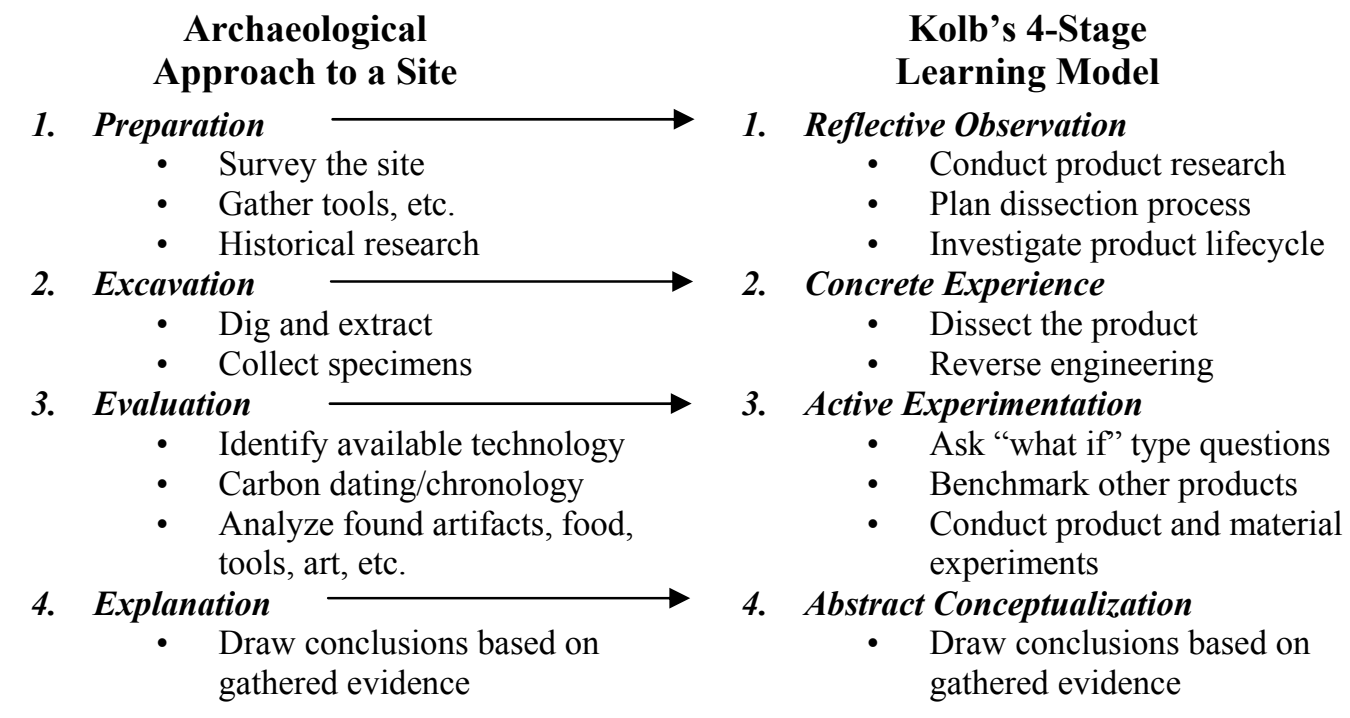

Figure 2. Mapping between Archaeological Exploration Phases and Kolb’s Model

In the next section, we present scalable learning materials, strategies, and educational innovations that we are implementing to develop students' understanding of the broader context of engineering. We also present the assessment of our implementation of these materials, including comparing the outcomes to the national Prototype to Production (P2P) study [25]. These learning materials provide representative cross-cultural study experiences to address global, economic, environmental, social issues in developing engineering solutions. 


\section{Course Implementation and Assessment}

In this section, we describe our implementation and assessment activities across both lower level and upper level courses. These courses and activities span three universities, are aimed at demonstrating the diverse kind of courses that PA can impact, and illustrate some scalable and repeatable pedagogical activities that instructors can use. All teaching materials presented in this section are available at the website www.productarchaeology.org.

\subsection{Preparation/Excavation Courses (Lower Level)}

In this section, we describe our implementation and assessment activities in lower level courses. These activities are aimed at the preparation and excavation activities within the PA paradigm.

\section{Penn State University}

Implementation Description:

Our experimentation with the PA paradigm at the lower level involved modifying the dissection and re-design curriculum in a selected section of the Introduction to Engineering Design (EDSGN 100) course, and subsequent experimental design to assess the impact of the modification against three other course sections: two of which also used product dissection but without the PA paradigm, and one that featured design activities without the dissection front-end. The course section that featured product dissection activities all used electric toothbrushes and coffee-makers as products. In the PA section, in addition to the dissection activities, PA was introduced as a way to ground and direct the dissection activities. For all dissection sections, upon completion of the dissection, re-design of a more sustainable electric toothbrush (with less environmental burden), and culturally and economically appropriate coffee-maker re-design for the Japanese kitchen were included as projects.

\section{Assessment:}

Following the implementation of the modifications in the classroom setting, using parts of the E2020 national student survey (developed as part of a separate NSF project \#0550608) along with some course specific questions, assessment of the introductory design course occurred in the spring 2010 semester. The assessment tool asked the students to evaluate the emphasis and impact that all their engineering courses have had on the following:

- ethical issues,

- life long learning,

- beliefs/values,

- cultural diversity,

- creativity,

- workforce trends,

- emerging technologies,

- practical use of theories,
- professional skills,

- communication skills,

- leadership skills,

- working in teams,

- project management,

- cultural context of engineering solutions,

- the impact of nonengineering fields,
- systems thinking,

- the application of knowledge from other fields to solve engineering problems,

- defining a design problem, and

- generating solutions to an engineering problem.

The survey then asked the students to evaluate the emphasis and impact that the introductory design course alone had on the same set of issues. The survey was administered to four course sections included in the study $(\mathrm{n}=92)$. 
The analysis focused on the relationship between the study scales (provided in Table 1), and the different levels and means of emphasizing global, societal, environmental, and economic issues in a design course setting, specifically four sections of the Introduction to Engineering Design (EDSGN 100) class. The study sought responses to the following questions:

1) Is there any difference between males and females in terms of these scales?

2) Is there any difference across students with different class standings (i.e., freshman, sophomore, etc.)?

3) Which course modules have been associated with global, societal, environmental, and economic issues as identified by students?

4) Can product archeology based dissection $\&$ redesign activities increase the awareness of our students in global, societal, environmental, and economic issues (i.e., what is the impact of teaching methods (sections)?

\section{Table 1. Survey Scales}

\begin{tabular}{cl}
\hline \hline \# & \multicolumn{1}{c}{ Scale } \\
\hline Scale 1 & Applying Math and Science \\
Scale 2 & Defining Problems and Generating Design Solutions \\
Scale 3 & Managing a Design Project \\
Scale 4 & Engineering Context \\
Scale 5 & Teamwork \\
Scale 6 & Communication \\
Scale 7 & Leadership \\
Scale 8 & Interdisciplinary Knowledge and Skills \\
Scale 9 & Recognizing Perspectives \\
Scale 10 & The Emphasis of all Taken Courses in Engineering on Some Topics in Engineering \\
Scale 11 & The Emphasis of all Taken Courses in Engineering on Professional Skills \\
Scale 12 & The Emphasis of all Taken Courses in Engineering on Problem Solving Skills \\
Scale 13 & The Emphasis of EDSGN 100 on Some Topics in Engineering \\
Scale 14 & The Emphasis of EDSGN 100 on Professional Skills \\
Scale 15 & The Emphasis of EDSGN 100 on Problem Solving Skills \\
\hline \hline
\end{tabular}

Validity of our scales has been already checked in preliminary work (as part of NSF project \#0550608 activities). Reliability can be estimated by four methods: the re-test method, the alternative-form method, the split-halves method, and the internal consistency method. The internal consistency method is the most suitable method for estimating reliability in our case as this method does not require splitting or repeating of items and Cronbach's alpha is the most popular reliability estimate [26]. As a general rule, reliability should be above 0.8. This means that the random measurement errors have a low effect on the correlations. Scale 7 (Leadership) has the lowest reliability among the other scales. The Cronbach's alpha of Scale 1 (Apply Math and Science) equals 0.840, which shows a good level of reliability.

With reference to the descriptive statistics, we can conclude that, by and large, there are no differences across sections, genders, or year in school. A General Linear Model (GLM) is used to test statistical significance of these differences. Table 2 shows two scales that have statistical significant differences across sections, scale 1 (Applying Math and Science) and scale 13 (The Emphasis of EDSGN 100 on Some Topics in Engineering). Because our subjects were predominantly first-year students, the significant differences across sections for scale 1 can be 
due to pre-college characteristics. Scale 13, however, specifically asks, how much the course they are in alone emphasize each of the following topics in engineering:

1. Ethical issues in engineering practice,

2. The importance of lifelong learning,

3. Examining my beliefs and values and how they affect my ethical decisions,

4. The value of gender, racial/ethnic, or cultural diversity in engineering,
5. Creativity and innovation,

6. Current workforce and economic trends

7. Emerging engineering technologies,

8. How theories are used in engineering practice.

Descriptive results reveal that the course section that did not include dissection had the higher average for this scale, perhaps due to the fact that discussion of these topics was time-wise affordable.

Very important point to note is that because most of the 92 student subjects were first year students, they have not taken many other engineering courses at the time of data collection, and hence, to a large extent, the absence of significance across mean values for paired scales is expected (e.g., scales 10 and 13 in Table 1). Indeed, when the data collection was replicated for a course that involved junior and senior students (ME 466), significant increases were registered across two scale pairs: scales 10 (3.56) and 13 (3.73) and scales 12 (3.58) and 15 (3.71). These jumps point to the positive impact of PA based curricular modifications relevant to increasing global, societal, environmental, and economic issues as perceived by students.

Table 2. Cronbach's Alpha and p-values

\begin{tabular}{|c|c|c|c|c|c|c|c|}
\hline$\#$ & $\begin{array}{c}\text { Cronbach's } \\
\text { Alpha }\end{array}$ & Gender & Section & Year & $\begin{array}{c}\text { Gender* } \\
\text { Section }\end{array}$ & $\begin{array}{c}\text { Gender* } \\
\text { Year }\end{array}$ & $\begin{array}{c}\text { Section* } \\
\text { Year }\end{array}$ \\
\hline Scale 1 & 0.840 & .324 & $\mathbf{. 0 3 6}$ & .432 & .761 & .177 & .520 \\
\hline Scale 2 & 0.911 & .471 & .072 & .225 & .222 & .208 & .680 \\
\hline Scale 3 & 0.832 & .496 & .749 & .164 & .295 & .414 & .776 \\
\hline Scale 4 & 0.883 & .807 & .297 & .315 & .306 & .982 & .876 \\
\hline Scale 5 & 0.915 & .139 & .728 & .699 & .505 & .299 & .829 \\
\hline Scale 6 & 0.854 & .565 & .974 & .358 & .257 & .711 & .925 \\
\hline Scale 7 & 0.432 & .309 & .885 & .799 & .473 & .739 & .883 \\
\hline Scale 8 & 0.797 & .686 & .465 & .542 & .737 & .712 & .438 \\
\hline Scale 9 & 0.636 & .326 & .132 & .805 & .463 & .733 & .789 \\
\hline Scale 10 & 0.859 & .595 & .075 & .747 & .329 & .893 & .558 \\
\hline Scale 11 & 0.820 & .733 & .484 & .833 & .494 & .914 & .536 \\
\hline Scale 12 & 0.822 & .651 & .174 & .424 & .216 & 1.000 & .773 \\
\hline Scale 13 & 0.879 & .096 &. $\mathbf{0 2 8}$ & .141 & .524 & .621 & .278 \\
\hline Scale 14 & 0.877 & .775 & .966 & .130 & .103 & .389 & .153 \\
\hline Scale 15 & 0.842 & .540 & .542 & .335 & .512 & .662 & .467 \\
\hline
\end{tabular}

In addition to the scale items presented above, we also sought to understand which course modules have been associated with global, societal, environmental, and economic issues as perceived by students. In a series of four open-ended questions, students were asked to identify the specific course modules; responses to these would either verify that the module modification achieved its goals, or not. We have tabulated each student response for each specific issue (i.e., relevance to increasing global awareness). A sample tabulation specific course segments for 
their perceived relevance to environmental concerns across all four course sections (A to D) is provided in Figure 3 where DP indicates 'design projects'. Sections A and B include dissection to redesign activities; section $\mathrm{C}$, includes design but not dissection; and section $\mathrm{D}$ involves the modified curriculum through PA grounded dissection.

\begin{tabular}{|c|c|c|c|c|c|c|c|c|c|c|c|c|}
\hline & Class Activity & Responses & $\begin{array}{l}\text { Duration } \\
\text { (Weeks) }\end{array}$ & Class Activity & Responses & \begin{tabular}{|l} 
Duration \\
(Weeks)
\end{tabular} & $\begin{array}{l}\text { Class } \\
\text { Activity }\end{array}$ & Responses & $\begin{array}{l}\text { Duration } \\
\text { (Weeks) }\end{array}$ & $\begin{array}{l}\text { Class } \\
\text { Activity }\end{array}$ & Responses & $\begin{array}{l}\text { Duration } \\
\text { (Weeks) }\end{array}$ \\
\hline & & & & P1 & & & \multirow{4}{*}{ DP1 } & \multirow{4}{*}{0.18} & \multirow{4}{*}{2} & DP1 & 0.41 & 2 \\
\hline $\mathbf{E}$ & DP1 & 0.33 & 2 & DP1 & 0.10 & 2 & & & & $\overline{\mathrm{DP} 2}$ & 0.72 & 2 \\
\hline $\begin{array}{l}\mathbf{n} \\
\mathbf{v}\end{array}$ & $\begin{array}{l}\text { Fire Extinguisher } \\
\text { Redesign Mini } \\
\text { Project }\end{array}$ & 0.24 & - & DP2 & 0.04 & -- & & & & $\begin{array}{l}\text { Geographic } \\
\text { Locations }\end{array}$ & 0.03 & -- \\
\hline i $\mathrm{C}$ & EMS Modeling & 0.05 & - & EMS Modeling & 0.04 & 0.67 & & & & CAD & 0.03 & 5 \\
\hline $\begin{array}{ll} & 0 \\
n & n\end{array}$ & $\begin{array}{l}\text { Practice Problem } \\
\text { of Water } \\
\text { Resource }\end{array}$ & 0.05 & -- & $\begin{array}{l}\text { Practice } \\
\text { Problem of } \\
\text { Water Resource }\end{array}$ & 0.12 & - & \multirow{4}{*}{ DP2 } & \multirow{4}{*}{0.06} & \multirow{4}{*}{3} & $\begin{array}{l}\text { Camera } \\
\text { Dissection }\end{array}$ & 0.03 & -- \\
\hline$m^{t}$ & Green Design & 0.05 & - & \begin{tabular}{|l|l|} 
Product \\
Dissection \\
\end{tabular} & 0.04 & - & & & & \multirow{4}{*}{$\begin{array}{l}\text { Green } \\
\text { Design }\end{array}$} & \multirow{4}{*}{0.24} & \multirow{4}{*}{0.50} \\
\hline $\begin{array}{ll}\mathbf{e} & \mathbf{x} \\
- & \mathbf{t} \\
\mathbf{n} & \end{array}$ & Energy Saving & 0.05 & - & \begin{tabular}{|l} 
Fire \\
Extinguisher \\
Redesign Mini \\
Project
\end{tabular} & 0.04 & -- & & & & & & \\
\hline $\mathbf{t}$ & $\begin{array}{l}\text { Product Design } \\
\text { Challenges }\end{array}$ & 0.10 & - & \begin{tabular}{|l|} 
Design \\
Problems
\end{tabular} & 0.04 & - & & & & & & \\
\hline $\begin{array}{l}a \\
1\end{array}$ & Readings & 0.05 & 15 & $\begin{array}{l}\text { Lab2-Noise and } \\
\text { Battery Life } \\
\text { Measurement }\end{array}$ & 0.12 & 15 & $\begin{array}{l}\text { In Class } \\
\text { Discussion }\end{array}$ & 0.12 & 15 & & & \\
\hline \multirow[t]{2}{*}{ of Res } & \multicolumn{3}{|c|}{16 out of 21} & \multicolumn{3}{|c|}{$\begin{array}{r}16 \text { out of } 25 \\
\end{array}$} & \multicolumn{3}{|c|}{10 out of 17} & \multicolumn{3}{|c|}{26 out of 29} \\
\hline & \multicolumn{3}{|c|}{ Section A } & \multicolumn{3}{|c|}{ Section B } & \multicolumn{3}{|c|}{ Section C } & \multicolumn{3}{|c|}{ Section D } \\
\hline
\end{tabular}

Figure 3. Sample Tabulation for Perceived Relevance of Course Content to Environmental Context

In Table 3, the ratio of the number of course segments that the students identified with the global, societal, environmental, and economic issues over the total number of students is shown. As it can be observed, the PA section (D) has the highest ratio of across all issues, which shows that the implemented modifications to the design curriculum were perceived as associated with global, societal, environmental, and economic issues.

Table 3. Ratio of the Total \# of Counts of Identified Course Segments to the Number of Students

\begin{tabular}{|l|c|c|c|c|}
\hline & A & B & C & D \\
\hline Global Context & 0.67 & 0.52 & 0.59 & 1.31 \\
\hline Economic Context & 0.86 & 0.64 & 0.47 & 1.28 \\
\hline Environmental Context & 0.90 & 0.60 & 0.29 & 1.48 \\
\hline Social Context & 0.90 & 0.68 & 0.41 & 1.21 \\
\hline
\end{tabular}

One last activity, embedded in the Production Dissection course (ME 420), was to have students collaboratively dissect appliances, and go through the PA cycle to understand the global, economic, environmental and societal impacts of these products. A complementary task also required students to relate the identified impacts to a design process. Sample charts produced by students are provided in Figure 4. While a statistical analysis is not done specific to this activity, it is apparent that, as facilitated, the activity engaged students in reflections pertaining to the focus areas. In future repetitions of this activity, statistical analyses will be conducted. 


\begin{tabular}{|c|c|c|c|c|c|c|c|c|c|c|c|c|}
\hline \multirow{2}{*}{ Product } & \multicolumn{3}{|c|}{ Global } & \multicolumn{3}{|c|}{ Economical } & \multicolumn{3}{|c|}{ Environmental } & \multicolumn{3}{|c|}{ Societal } \\
\cline { 2 - 13 } & + & $\mathrm{N}$ & - & + & $\mathrm{N}$ & - & + & $\mathrm{N}$ & - & + & $\mathrm{N}$ & - \\
\hline Bicycles & 13 & 2 & & 5 & 3 & 1 & 8 & 3 & 2 & 7 & 3 & 1 \\
\hline $\begin{array}{l}\text { Washing } \\
\text { machine }\end{array}$ & & 1 & & & 1 & & & & 1 & & & \\
\hline Dishwasher & 1 & 1 & & & & & & & & 2 & & \\
\hline Refrigerator & 1 & & & & & 1 & & & & 1 & & \\
\hline Television & 2 & 1 & & & 1 & & 1 & & 1 & & 3 & 3 \\
\hline IC Engine & 2 & & 3 & 2 & 4 & 1 & 5 & & 4 & 3 & & 6 \\
\hline
\end{tabular}

\begin{tabular}{|c|c|c|c|c|}
\hline & \multirow{2}{*}{ Impacts } & \multicolumn{3}{|c|}{ Design has an Impact } \\
\cline { 3 - 5 } & Design & + & $\mathrm{N}$ & - \\
\hline Bicycles & 17 & 33 & 11 & 4 \\
\hline $\begin{array}{c}\text { Washing } \\
\text { machine }\end{array}$ & $\mathbf{5}$ & 0 & 2 & 1 \\
\hline Dishwasher & $\mathbf{6}$ & 3 & 1 & 0 \\
\hline Refrigerator & $\mathbf{6}$ & 2 & 0 & 1 \\
\hline Television & 2 & 3 & 5 & 4 \\
\hline IC Engine & 3 & 12 & 4 & 14 \\
\hline
\end{tabular}

Figure 4. Collaborative Dig Exercise

We also implemented PA instructional and assessment activities in upper level design courses, which are described in the next section.

\subsection{Evaluation/Explanation Courses (Upper Level)}

In this section, we describe our implementation and assessment activities in upper level courses. These activities are aimed at the evaluation and explanation activities within the PA paradigm.

\section{University at Buffalo - SUNY}

Implementation Description:

We have developed and implemented teaching modules for a senior design course (MAE451: Design Process and Methods). This course focuses on teaching the fundamental theories of a design process, starting from problem clarification to product support. The design process representing the core of the semester activities is shown in Figure 5. The innovative new modules that we have developed focus on addressing global, social, environmental, and economic issues by leveraging three of the National Academy of Engineering's Grand Challenges [27]. The pedagogical focus is on the Explanation phase of the framework, although in the process of designing and drawing conclusions, the students many times perform tasks and experience opportunities related to the Preparation, Excavation, and Evaluation phases.

The month-long modules (i.e., mini-projects) focus on the following challenges:

1) Making Solar Energy Economical: Students experience significant opportunities to understand environmental, global, economic, and social impacts on developing customer requirements.

2) Provide Access to Clean Water: Students experience significant opportunities to understand environmental, global, economic, and social impacts on developing design concepts.

3) Restore and Improve Urban Infrastructure: Students experience significant opportunities to understand environmental, global, economic, and social impacts on embodying design solutions.

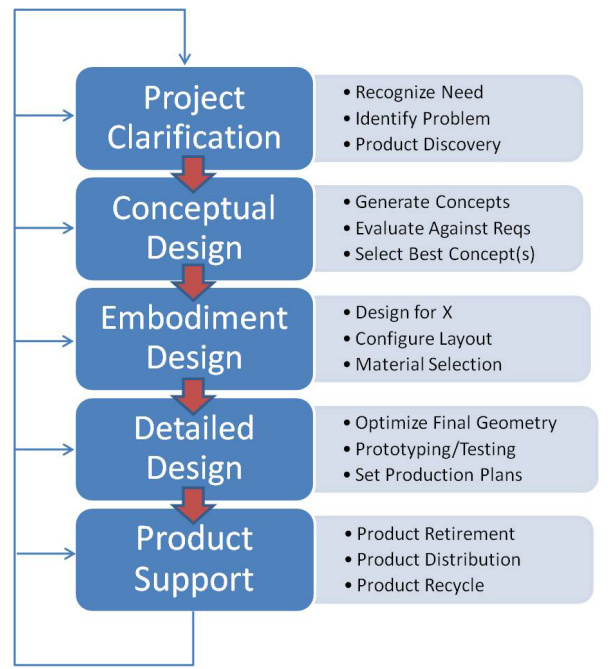

Figure 5. Design Process 
The mini-project descriptions are shown in Appendix A. These can also be accessed at the project website: www.productarchaeology.org. The mini-projects progressively allow the students to experience more of the design process in Figure 5. For instance, in mini-project 1, the deliverable is simply the design problem, including all the customer requirements and engineering specifications. Students must consider environmental, social, economic, and social issues in the development of their customer requirements. In mini-project 2, the students must perform all the same tasks as mini-project 1, but also must develop a conceptual solution to the problem. In mini-project 3, the students must perform all the same tasks as mini-project 2, but also must embody and detail their design solutions. Emphasis all semester is placed on innovative, multi-cultural, scalable, environmentally aware, economically feasible, and globally relevant solutions with significant social impact.

At the close of each month long mini-project, the student groups present a one-minute report-out using one slide. Samples of these report-out slides are shown in Figure 6.
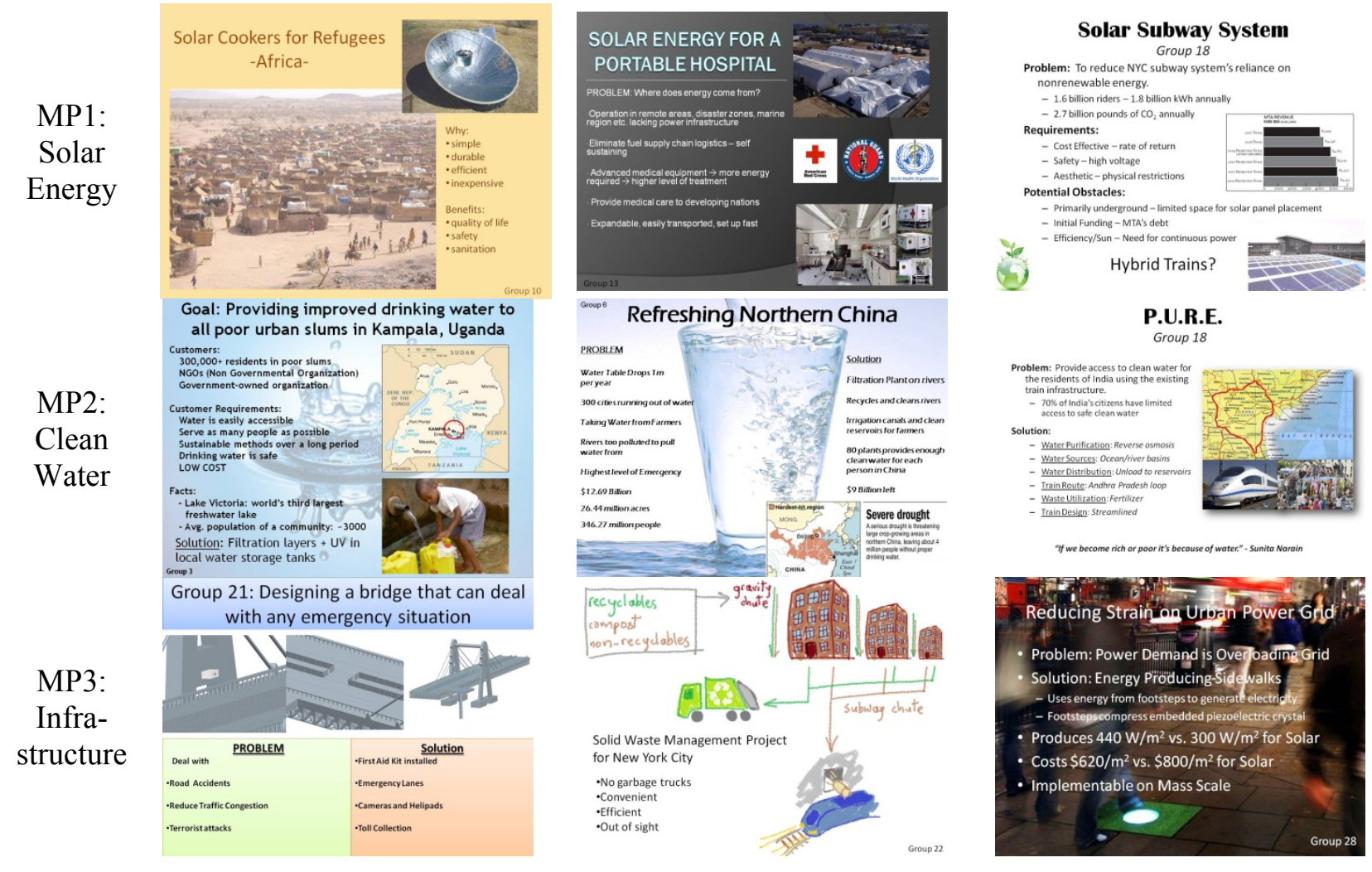

Figure 6. Report-Out Slide Samples

$\underline{\text { Assessment }}$

Using parts of the E2020 national student survey along with some course specific questions, assessment of the senior design course occurred in the fall 2009 semester (fall 2010 results were not available yet). The most relevant results are reported in Table 4 . The students $(n=106)$ were asked to evaluate how much their two sets of courses had emphasized three groups of learning objectives: 1) Topics in Engineering, 2) Professional Skills, and 3) Problem Solving Skills.

The first set of courses the students were asked to evaluate was all the other engineering courses besides MAE451 and the second set was MAE451 alone. This was done to isolate the impact of 
MAE451 on these learning objectives. A five-point Likert scale was used: little/no emphasis (1), slight (2), moderate (3), strong (4), and very strong (5). In Table 4, the analysis of the data is shown. The columns display the average score for all the other courses, the average score for MAE451, the $p$-value from the hypothesis test, and the rank in the group. What is clearly evident is that MAE451 placed a greater emphasis on almost every issue compared to the other courses in the curriculum. The only issue that did not have a significant difference was 'How theories are used in engineering practice' in the set of Topics in Engineering.

Further, the bold issues in each represent issues directly relevant to ABET's Outcome h, demonstrating how significant an impact the new product archaeology modules introduced in MAE451 had on the students' understanding of the global, social, environmental, and economic issues in engineered solutions.

Table 4. Impact Results and Statistical Significance

\begin{tabular}{|c|c|c|c|c|}
\hline & $\begin{array}{c}\text { All other } \\
\text { courses (avg) }\end{array}$ & $\begin{array}{c}\text { MAE451 } \\
\text { (avg) }\end{array}$ & p-value & $\begin{array}{l}\text { Rank in } \\
\text { group }\end{array}$ \\
\hline \multicolumn{5}{|l|}{ Topics in Engineering } \\
\hline Emerging engineering technologies & 3.25 & 4.45 & $<0.001$ & 1 \\
\hline Creativity and innovation & 3.45 & 4.81 & $<0.001$ & 2 \\
\hline $\begin{array}{l}\text { Current workforce and economic trends } \\
\text { (globalization, outsourcing, etc.) }\end{array}$ & 2.84 & 3.91 & $<0.001$ & 3 \\
\hline $\begin{array}{l}\text { Examining my beliefs and values and how they } \\
\text { affect my ethical decisions }\end{array}$ & 2.56 & 3.22 & $<0.001$ & 4 \\
\hline Ethical issues in engineering practice & 2.80 & 3.36 & $<0.001$ & 5 \\
\hline $\begin{array}{l}\text { The value of gender, racial/ethnic, or cultural } \\
\text { diversity in engineering }\end{array}$ & 2.50 & 3.01 & $<0.001$ & 6 \\
\hline The importance of life-long learning & 3.32 & 3.79 & $<0.001$ & 7 \\
\hline How theories are used in engineering practice & 3.71 & 3.87 & 0.1898 & 8 \\
\hline \multicolumn{5}{|l|}{ Professional Skills } \\
\hline $\begin{array}{l}\text { Project management skills (budgeting, } \\
\text { monitoring progress, managing people, etc.) }\end{array}$ & 3.08 & 4.35 & $<0.001$ & 1 \\
\hline Working effectively in teams & 3.74 & 4.63 & $<0.001$ & 2 \\
\hline Leadership skills & 3.11 & 4.04 & $<0.001$ & 3 \\
\hline Written and oral communication skills & 3.31 & 4.31 & $<0.001$ & 4 \\
\hline $\begin{array}{l}\text { Professional skills (knowing codes and standards, } \\
\text { being on time, meeting deadlines, etc.) }\end{array}$ & 3.15 & 3.89 & $<0.001$ & 5 \\
\hline \multicolumn{5}{|l|}{ Problem Solving Skills } \\
\hline $\begin{array}{l}\text { Generating and evaluating ideas about how to } \\
\text { solve an engineering problem }\end{array}$ & 3.49 & 4.64 & $<0.001$ & 1 \\
\hline $\begin{array}{l}\text { Understanding how an engineering solution can } \\
\text { be shaped by environmental, cultural, economic, } \\
\text { and other considerations }\end{array}$ & 3.12 & 4.26 & $<0.001$ & 2 \\
\hline Defining a design problem & 3.46 & 4.61 & $<0.001$ & 3 \\
\hline $\begin{array}{l}\text { Applying knowledge from other fields to solve an } \\
\text { engineering problem }\end{array}$ & 2.75 & 3.71 & $<0.001$ & 4 \\
\hline $\begin{array}{l}\text { Understanding how non-engineering fields can } \\
\text { help solve engineering problems }\end{array}$ & 2.52 & 3.45 & $<0.001$ & 5 \\
\hline Systems thinking & 3.39 & 3.76 & $<0.001$ & 6 \\
\hline
\end{tabular}




\section{Northwestern University}

\section{Implementation Description}

At Northwestern University, we implemented a product archaeology lab exercise and GSEE reflection activities, both in the context of students' design project work in a senior design course (ME398). There were five industry-sponsored projects in the course: 1) Low Energy Release Mechanism (LE), 2) Adaptive Dive Gear for Handicapped (ADG), 3) Hybrid Truck Battery (HT), 4) Meat-Casing Removal, and 5) Multifunctional Open-it Tool (Open-IT). In order to accommodate the range of projects in the class we offered students several options for "excavation" in the product-archaeology lab exercise such as (a) an existing competitor product, (b) previous or current version of their project's product, (c) an add-on to their designed product that would be mounted/installed, or (d) a different product that serves a similar function. We embedded this flexibility into the lab exercise in order to accommodate the range of projects/products in the class. Examples of two objects that were excavated during the lab exercise are shown in Figure 7. In addition to the lab exercise, we included several opportunities for students to think about and reflect on how GSEE topics related to their design project.

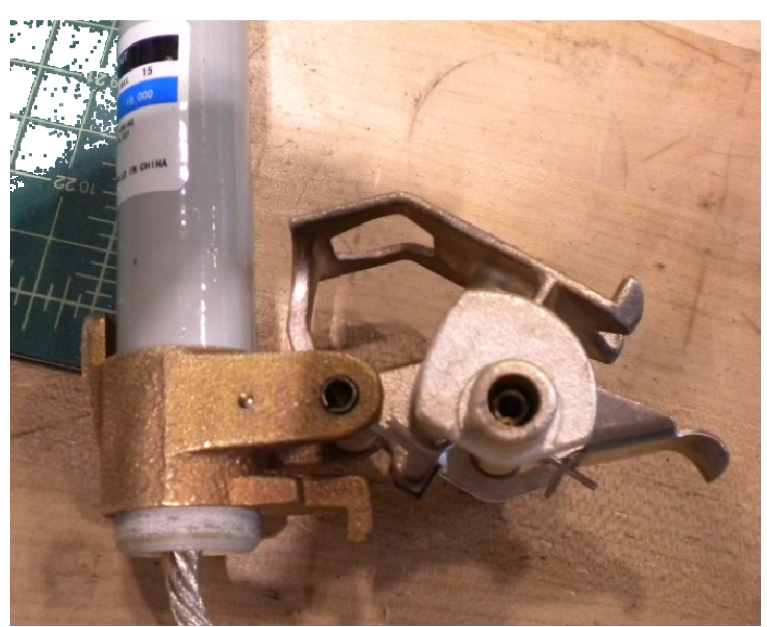

a. Existing Quick Release Mechanism (LE)

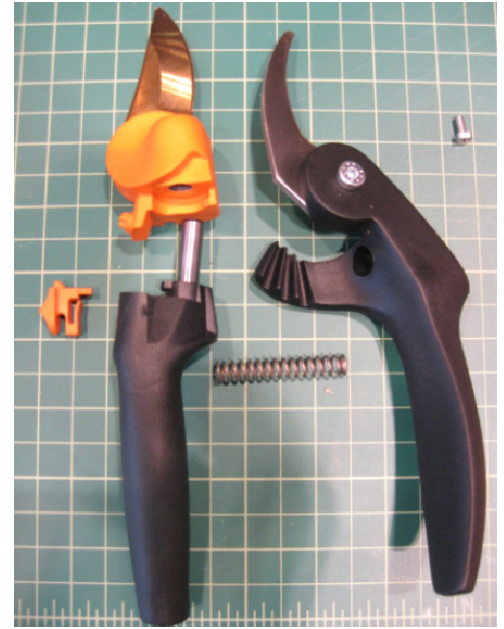

b. Open-in in the Market (Open-IT)

Figure 7. Sample Product-Archaeology Objects

\section{Assessment:}

The lab exercise embedded two main deliverables that formed one part of our assessment, (1) "Product Archaeology Postulation" (due before the archaeology lab session), and (2) "Product Archaeology Lab" report (due after the lab session). The postulation included several reflection questions that enabled us to collect baseline information regarding students' pre-ideas about GSEE issues. The lab report asked students similar questions as the postulation but also required teams to report on the details of their excavation such as if there were any issues associated with assembly/disassembly of their product. In addition to the lab exercise assignment students were given a survey at the end of the quarter to collect their perceptions of how the excavation activities contributed to their understanding of GSEE topics as well as engineering-design topics in general. As shown in Table 5, the survey used a five-point Likert scale ranging from 1 strongly disagree 5 - strongly agree and included items to separate global, social, environmental, and economic contexts in order to capture potential variations along each aspect. 
Table 5. Rating of the Impact of the Project Archaeology Exercise

\begin{tabular}{|c|c|c|c|c|c|}
\hline \multirow[b]{2}{*}{ Survey items } & \multicolumn{4}{|c|}{ Avg. item scores for teams: } & \multirow{2}{*}{$\begin{array}{l}\text { Overall } \\
\text { scores }\end{array}$} \\
\hline & ADG & HT & LE & $\begin{array}{l}\text { Open } \\
\text {-IT }\end{array}$ & \\
\hline $\begin{array}{l}\text { Determine the types and numbers of components and } \\
\text { subsystems required to design (Eng 1) }\end{array}$ & 3.5 & 3.33 & 2.22 & 4.5 & 3.31 \\
\hline Consider relevant design criteria (Eng 2) & 3.0 & 3.0 & 3.2 & 4.0 & 3.31 \\
\hline $\begin{array}{l}\text { Relate customers' needs to components and their associated } \\
\text { functionality (Eng } 3 \text { ) }\end{array}$ & 3.0 & 2.0 & 2.8 & 4.1 & 3.03 \\
\hline Generate design alternatives (Eng 4) & 2.5 & 2.67 & 3.8 & 4.5 & 3.44 \\
\hline Effectively evaluate alternatives (Eng 5) & 2.75 & 2.67 & 3.8 & 3.5 & 3.25 \\
\hline Describe how global context influences design (GSEE 1) & 1.85 & 1.87 & 2.2 & 2.55 & 2.14 \\
\hline Describe how economic context influences design (GSEE 2) & 3.0 & 2.33 & 3.2 & 3.25 & 3.0 \\
\hline $\begin{array}{l}\text { Describe how environmental context influences design } \\
\text { (GSEE 3) }\end{array}$ & 1.65 & 2.0 & 2.6 & 2.65 & 2.26 \\
\hline Describe how societal context influences design (GSEE 4) & 2.35 & 2.07 & 3.24 & 4.2 & 3.04 \\
\hline $\begin{array}{l}\text { Build confidence in analyzing the impact of global, } \\
\text { economic, environmental, and societal considerations on } \\
\text { design (GSEE 5) }\end{array}$ & 1.95 & 2.0 & 2.8 & 3.25 & 2.55 \\
\hline
\end{tabular}

To conduct our analysis we grouped the items in the survey according to "GSEE" and "engineering" related issues in order to see if there might be differences along these two dimensions. For the current paper, we report assessment results from only the survey data. The survey data indicates that most of the students strongly agree that the archaeology exercise is very helpful for determining the types and numbers of components and subsystems required in the design (Eng 1), considering relevant design criteria (Eng 2), generating and evaluating design alternatives (Eng $4 \& 5$ ). They somewhat agree that the exercise is helpful for relating customers needs to components and their associated functionality (Eng 3) (see Fig. 8).

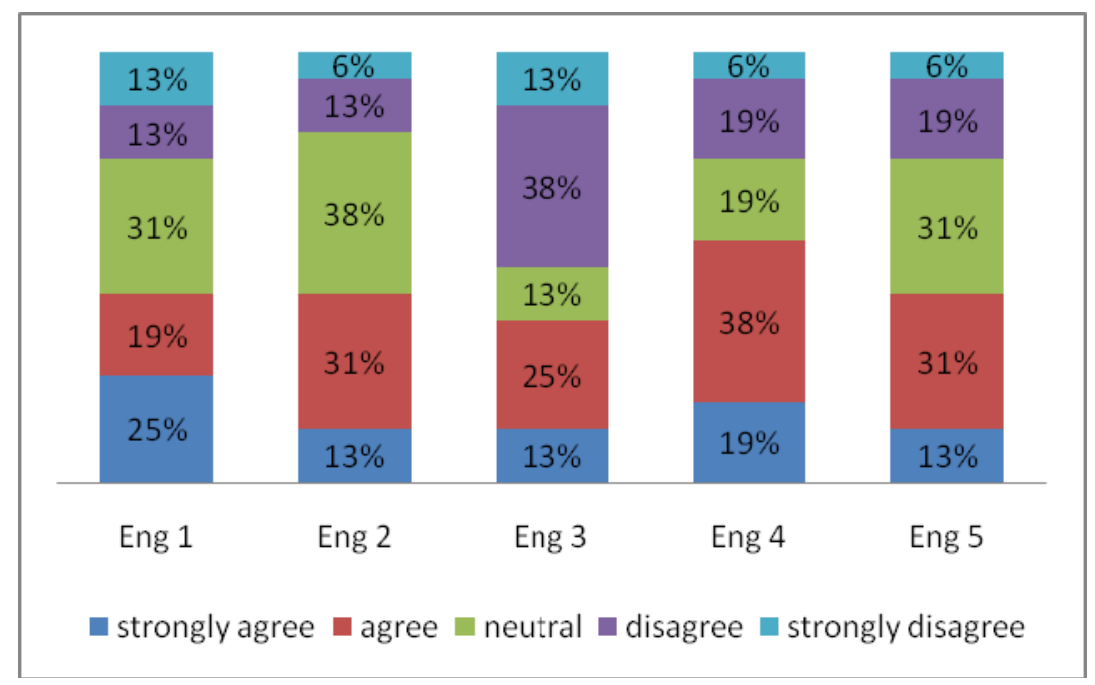

Figure 8. Comparison of the Five Engineering Items 
When looking at the scores for the GSEE items we could observe a somewhat lower percentage of student agreement (see Fig. 9).

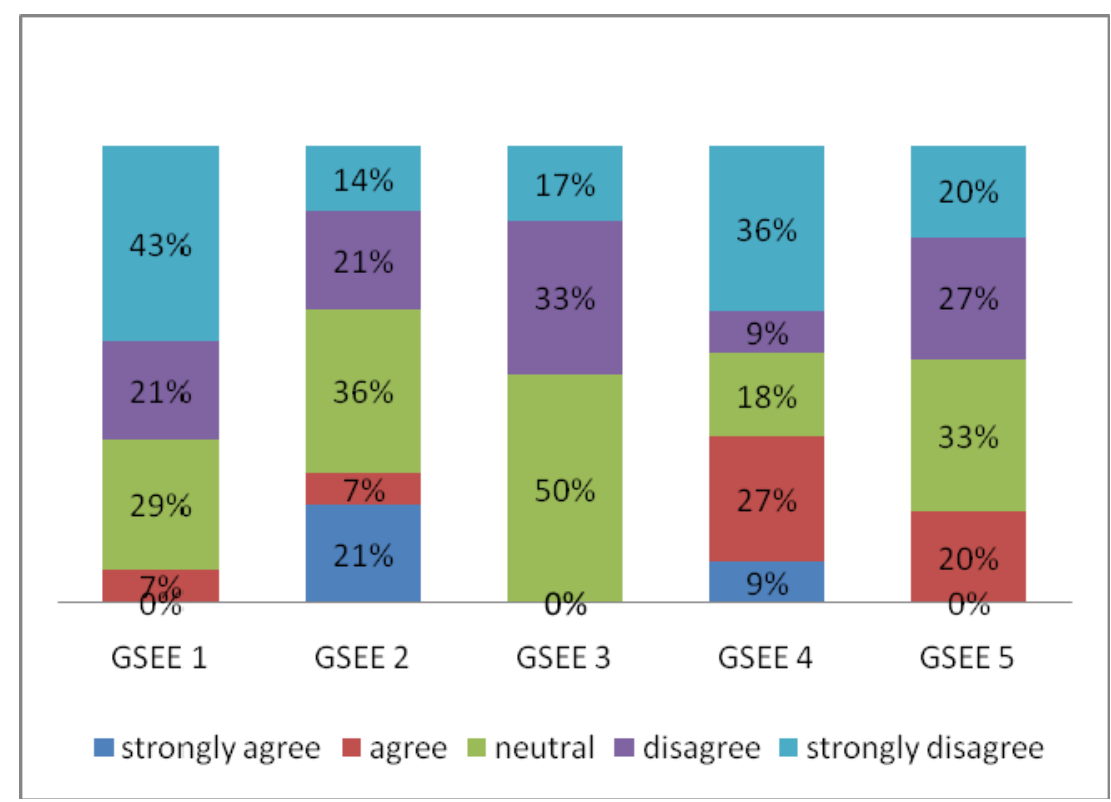

Figure 9. Comparison of the Five GSEE Items

Therefore, to investigate if the differences are statistically significant we conducted an analysis of variance (ANOVA) to compare engineering and GSEE item score means. Table 6 shows that GSEE items 1 (global), 3 (environmental) and 5 (general GSEE confidence) scored significantly lower compared to the engineering items.

Table 6. Comparison Between Engineering and GSEE Item Scores

\begin{tabular}{|cccccc|}
\hline & ENG 1 & ENG 2 & ENG 3 & ENG 4 & ENG 5 \\
\hline GSEE 1 & $-55.0 \% *$ & $-55.0 \% *$ & $-41.5 \% *$ & $-60.8 \% *$ & $-52.0 \% *$ \\
GSEE 2 & $-10.4 \%$ & $-10.4 \%$ & $-0.8 \%$ & $-14.6 \%$ & $-8.3 \%$ \\
GSEE 3 & $-46.4 \% *$ & $-46.4 \% *$ & $-33.7 \% *$ & $-51.9 \% *$ & $-43.6 \% *$ \\
GSEE 4 & $-9.1 \%$ & $-9.1 \%$ & $0.4 \%$ & $-13.2 \%$ & $-7.0 \%$ \\
GSEE 5 & $-29.9 \%$ & $-29.9 \% *$ & $-18.6 \%$ & $-34.8 \% *$ & $-27.5 \%$ \\
\hline${ }^{*}<.001$ & & & & &
\end{tabular}

Results show that on average students perceive that the excavation exercises helped them to understand engineering issues, even more so than GSEE issues, see Figure 8, Figure 9, Figure 10 and Table 6. This is an interesting finding in that the product archaeology approach not only supports understanding of GSEE, but aspects of the design process as well. However, we did see variations by project. In particular, our findings suggest that a more consumer-oriented product, such as LE \& Open IT, results in higher GSEE ratings. As we continue this work, we will use data from the projects reports to perhaps shed light on why this might be the case. 


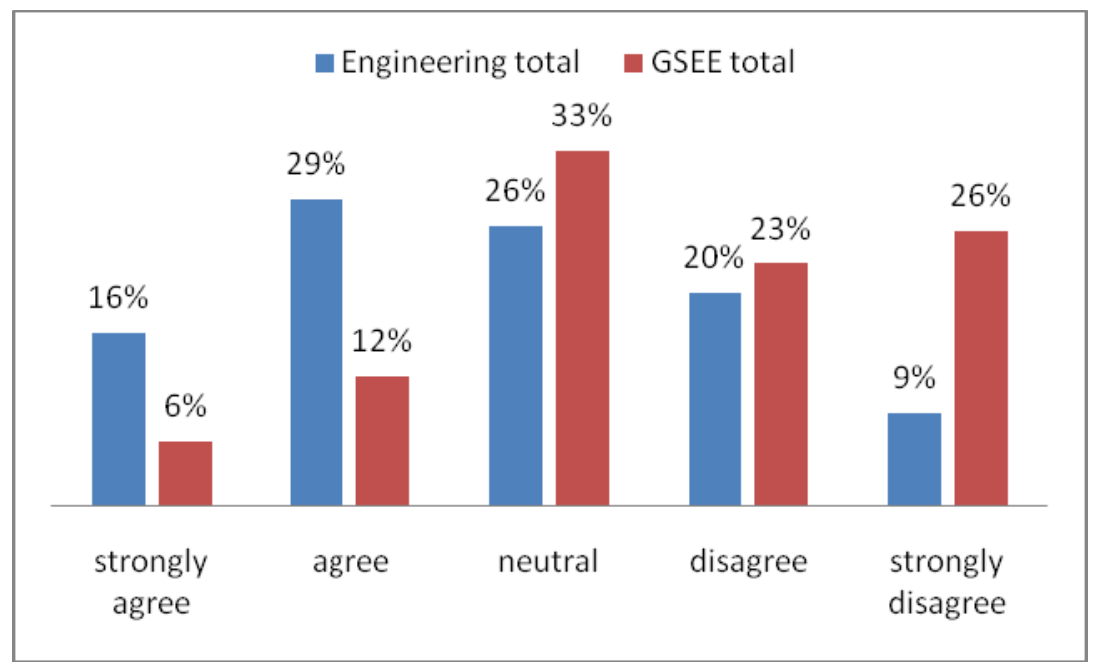

Figure 10. Summary of End-of Quarter Survey Results - Impact on Understanding GSEE and Engineering Issues

\section{Conclusions}

We are synthesizing concepts from archaeology with advances in cyber-enhanced product dissection to implement new educational innovations that will directly address the challenging global, economic, environmental, and societal concerns associated with ABET Outcome h. The crowded engineering curricula provide few opportunities to offer meaningful experiences to address this outcome, and most departments relegate this requirement to an early cornerstone or later capstone design experience. As a result, students' achievements towards this outcome are most often lacking. We address this issue by providing scalable learning materials, strategies, and educational innovations that develop students' understanding of the broader context of engineering. We are establishing product archaeology - the process of reconstructing the lifecycle of a product including the customer requirements, design specifications, and manufacturing processes used to produce it in order to understand the decisions that led to its development - as our scalable and sustainable pedagogical foundation for engineering.

Our activities have revealed some valuable insights that instructors can immediately take advantage of and that we can use to shape future studies:

- Product Archaeology activities provide valuable opportunities for students to experience, evaluate, and implement global, social, environmental, and economic issues in engineering design.

- These opportunities, as implemented in core design courses, provide effective support to meet ABET outcome $h$ in an engineering curriculum.

- Consumer-oriented products provide the most relevant experiences for students to relate global, social, environmental, and economic issues to engineering design knowledge.

- Students greatly enjoy learning about the global, social, environmental, and economic challenges in engineering design and integrating these issues with technical engineering issues in order to develop an effectively engineered system with broad impact.

While educating a new generation of students on knowledge areas critical to their survival and success as engineers such as globalization, economic forces, environmental impacts, and social concerns is a significant impact in and of itself, the pedagogical value of the project has even 
further reaching implications. For instance, a cursory search of available engineering jobs using key words of "mechanical engineer" at the General Electric website resulted in jobs in the following countries: Brazil, Germany, India, France, Hungary, United Kingdom, Canada, China, Switzerland, Mexico, Norway, Qatar, and Singapore. Engineering is no longer a profession driven solely by technical issues - engineers must now understand the global implications of their decisions on social communities, corporate economics, and the environment. This project is enriching the limited exposure that students currently get to many of these topics, and they will also provide opportunities to demonstrate how engineering careers "makes a difference" in the world, which has been shown by the National Academies to be more likely to attract young people to engineering than emphasizing the challenge of math and science skills.

Current work includes continued development of instructional material, course plans, and assessment strategies across the entire undergraduate design curriculum. These materials will be disseminated through continuing workshops for faculty and students and through our product website: www.productarchaeology.org.

\section{Acknowledgements}

This work was funded under a Phase II grant from the Course, Curriculum, and Laboratory Instruction (CCLI) program at the National Science Foundation (grants \# DUE-0920259, 0920047, and 0919724).

\section{Bibliographic Information}

[1] Engineering Accreditation Commission, 1999, Criteria for Accrediting Engineering Programs. Baltimore, MD, ABET, http://www.abet.org/eac/eac.htm.

[2] McMillon, B., 1991, The Archaeology Handbook: A Field Manual and Resource Guide, New York, John Wiley \& Sons.

[3] Renfrew, C. and Bahn, P., 2004, Archeology: Theories, Methods, and Practice, New York, Thames \& Hudson.

[4] Ulrich, K. T. and Pearson, S., 1998, "Assessing the Importance of Design through Product Archaeology," Management Science, 44(3), 352-369.

[5] Ogot, M., Kremer, G., Lamancusa, J. and Simpson, T. W., 2008, "Developing a Framework for Disassemble/Analyze/Assemble (DAA) Activities in Engineering Education," Journal of Design Research, 7(2), 120-135.

[6] Otto, K. N. and Wood, K. L., 2001, Product Design: Techniques in Reverse Engineering and New Product Development, Upper Saddle River, NJ, Prentice Hall.

[7] Ingle, K. A., 1994, Reverse Engineering, New York, McGraw-Hill.

[8] Dattakumar, R. and Jagadeesh, R., 2003, "A Review of Literature on Benchmarking," Benchmarking, 10(3), 176-209.

[9] Harrington, H. J., 1996, The Complete Benchmarking Implementation Guide: Total Benchmarking Management, New York, NY, McGraw-Hill.

[10] Hoffman, C., 2006, The Teardown Artists, Wired, 136-140.

[11] Sheridan, D., Graman, B., Beck, K. and Harbert, J., 2001, Improving From the Inside Out, Appliance Manufacturer. January.

[12] Carlson, B., Schoch, P., Kalsher, M. and Racicot, B., 1997, "A Motivational First-Year Electronics Lab Course," ASEE Journal of Engineering Education, 86(4), 357-362.

[13] Beaudoin, D. L. and Ollis, D. F., 1995, "A Product and Process Engineering Laboratory for Freshmen," ASEE Journal of Engineering Education, 84(3), 279-284. 
[14] Sheppard, S. D., 1992, "Mechanical Dissection: An Experience in How Things Work", Proceedings of the Engineering Education Conference: Curriculum Innovation \& Integration, Santa Barbara, CA.

[15] Sheppard, S., 1992, "Dissection as a Learning Tool", Proceedings of the IEEE Frontiers in Education Conference, Nashville, TN, IEEE.

[16] Fincher, C., 1986, "Trends and Issues in Curricular Development in Higher Education", Handbook of Theory and Research, Smart, J., New York, Agathon, 2, 275-308.

[17] Nicolai, L. M., 1995, "Designing a Better Engineer," Aerospace America, 30(4), 30-33.

[18] Brereton, M. F., 1998, "The Role of Hardware in Learning Engineering Fundamentals: An Empirical Study of Engineering Design and Dissection Activity", Mechanical Engineering, Stanford University, Palo Alto, CA.

[19] Lamancusa, J., Torres, M., Kumar, V. and Jorgensen, J., 1996, "Learning Engineering by Product Dissection", ASEE Conference, Washington D.C., ASEE.

[20] Ahlgren, D. J., 2001, "Fire-fighting Robots and First-year Engineering Design: Trinity College Experience", Proceedings of the ASEE/IEEE Frontiers in Education Conference, Reno, NV, ASEE, Paper No. S2E-1.

[21] Dalrymple, O. and Evangelou, D., 2006, "The Role of Extracurricular Activities in the Education of Engineers", International Conference on Engineering Education, San Juan, Puerto Rico, Paper No. T4K-24.

[22] Briedis, D., 2002, "Developing Effective Assessment of Student Professional Outcomes," International Journal of Engineering Education, 18(2), 208-216.

[23]Biney, P., 2007, "Assessing ABET Outcomes Using Capstone Design Courses", 2007 ASEE Annual Conference \& Exposition, ASEE, Paper No. AC2007-1556.

[24] Kolb, D., 1984, Experiential Learning: Experience as the Source of Learning and Development, Englewood Cliffs, NJ, Prentice Hall.

[25] Prototype to Production (P2P), http://www.ed.psu.edu/educ/e2020/p2p, accessed January 19, 2011.

[26] Carmines, E. G., and Zeller, R. A., 1979, Reliability and Validity Assessment. Newbury Park, CA: Sage Publications.

[27] National Academy of Engineering, 2008, "Grand Challenges for Engineering," National Academy of Sciences. (available at www.engineeringchallenges.org/File.aspx?id=11574, accessed January 19, 2011) 


\section{Appendix A - University at Buffalo - SUNY Mini-Projects}

mini.project 1

making solar energy economical

\section{due wed oct 6}

\section{description}

As a source of energy, nothing matches the sun. It out-powers anything that human technology could ever produce. Only a small fraction of the sun's power output strikes the Earth, but even that provides 10,000 times as much as all the commercial energy that humans use on the planet. However, while there is adequate solar energy available, there are numerous technical and economic hurdles to making it viable as a reliable and sustainable energy source.

task

Your task is to identify a design problem related to this grand challenge. While the source of this problem could be technical, economic, social, and/or environmental, fully defining the problem will most likely require consideration of all of these aspects. This will take substantial research, dialogue, and thinking. Your report needs to include the following:

- A clear statement of the design problem including the appropriate context, customer group, and regional consideration.

- A comprehensive set of customer requirements that cover the major customer groups for the problem.

- A set of engineering specifications that address the customer requirements.

- A House of Quality $(\mathrm{HoQ})$ that relates the customer requirements to the engineering specifications. The expectations for the HoQ include the left side (the WHATs), importance for the WHATs, the top side (the HOWs), and the roof (HOW vs. HOW). HoQ templates in xls can be found here: $\mathrm{http}$ ://www.qfdonline.com/templates/qfd-and-house-of-quality-templates/.

- A set of conclusions, major trends, and problem insights from the HoQ.

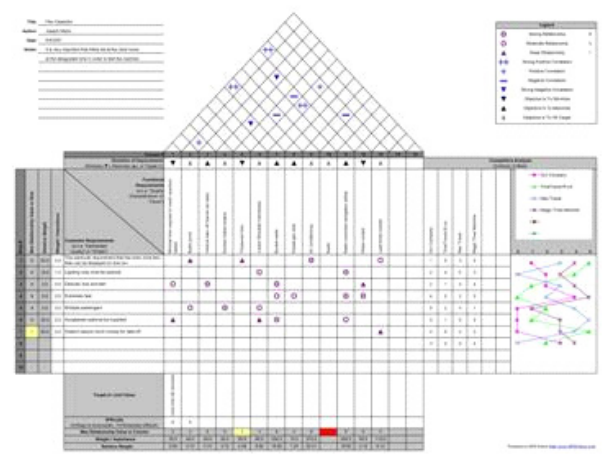

\section{resources}

Listed here are some starting points for your research. You should go well beyond these resources using your own research, experiences, and knowledge.

- Lewis, N.S. 2007. Toward Cost-Effective Solar Energy Use. Science 315(5813): 798-801. DOI: 10.1126/science.1137014 (http://www.sciencemag.org/cgi/content/full/315/5813/798).

- The Solar America Initiative (http://www1.eere.energy.gov/solar/solar_america/index.html). Check out the publications link for some excellent technology roadmaps.

- Brahic, C., 2007, "Solar power schemes could protect nature reserves", NewScientist, 29 April, (http://www.newscientist.com/article/dn11740-affordable-solar-power-brings-light-to-india. html)

- "Bill Gross on new energy," http://www.ted.com/index.php/talks/bill gross on new energy.html (also see related company http://www.esolar.com/).

- Ananthaswamy, A., 2009, "Solar power schemes could protect nature reserves", NewScientist, 13 March, http://www.newscientist.com/article/mg20126992.900-solar-power-schemes-couldprotect-nature-reserves.html.

Mini-Project 1 Description 


\section{description}

The world's water supplies are facing new threats; affordable, advanced technologies could make a difference for millions of people around the world. Lack of clean water is responsible for more deaths in the world than war. About 1 out of every 6 people living today do not have adequate access to water, and more than double that number lack basic sanitation, for which water is needed. Some countries have far more water than their population needs while in others, half the population does not have access to safe drinking water. By some estimates, each day nearly 5,000 children worldwide die from diseases resulting from unclean sanitation water. The new threats to the world's water supplies demand affordable and advanced design solutions that could impact millions of people around the world.

\section{tasks}

1 Your first task is, in the same manner as Mini-Project 1, to identify a design problem related to this grand challenge. While the source of this problem could be technical, economic, social, and/or environmental, fully defining the problem will most likely require consideration of all of these aspects. This will take substantial research, dialogue, and thinking. This task will require the following:

- A clear statement of the design problem including the appropriate context, customer group, and regional consideration.

- A comprehensive set of customer requirements that cover the major customer groups for the problem.

- A set of engineering specifications that address the customer requirements.

- A House of Quality (HoQ) that relates the customer requirements to the engineering specifications. The expectations for the HoQ include the left side (the WHATs), importance for the WHATs, the top side (the HOWs), and the roof (HOW vs. HOW). Explain and discuss the major trends and findings from the house.

2 Your second task is to generate a set of design alternatives for your design problem. The more alternatives you generate, the better you will do on this portion of the project. Your methods of generating the concepts should be clearly discussed.

3 The third task is to select the most promising design alternative. The criteria along with the method you use to make this evaluation must be clearly presented. This evaluation may require narrowing down the initial set using more qualitative filters until a quantitative assessment can be done on a smaller number of alternatives.

\section{resources}

Listed here are some starting points for your research. You should go well beyond these resources using your own research, experiences, and knowledge.

- World Health Organization (WHO)/UNICEF Joint Monitoring Programme for Water Supply and Sanitation, 2005, "Water for Life: Making It Happen," Paris: WHO Press. (http://www.who.int/water_sanitation_health/monitoring/jmp2005/en/index.html)

- Specter, M., 2006, "The Last Drop: Confronting the Possibility of a Global Catastrophe," The New Yorker, Oct. 23. (http://www. newyorker.com/archive/2006/10/23/061023fa fact1?currentPage=all)

- Pereira, T., 2009, "Sustainability: An Integral Engineering Design Approach," Renewable and Sustainable Energy Reviews, Vol. 13, No. 5, pp. 1133-1137. (UBLearns)

- The Center of Advanced Materials for the Purification of Water with Systems, University of Illinois - Urbana-Champaign, http://www.watercampws.uiuc.edu/.

- Gray, N.F., 2008, Drinking Water Quality: Problems and Solutions, Cambridge University Press.

\section{Mini-Project 2 Description}




\section{mini.project 3 restore and improve urban infrastructure}

\section{description}

America's infrastructure, along with those of many other countries, is aging and failing. Engineers of the 21st century face the formidable challenge of modernizing the fundamental structures that support civilization. This challenge is magnified by the fact that the way people communicate, move, work, and play are changing. Development of new cyber- and energy-infrastructures will increase the challenges...and perhaps the opportunities. The problem is particularly acute in urban areas, where growing populations stress society's support systems, and natural disasters, accidents, and terrorist attacks threaten infrastructure safety and security. Also, in many parts of the world, basic infrastructure needs are still being established and therefore engineers will be challenged to design instead of retrofit infrastructures appropriately. Bottom line, good design is needed to create more sustainable urban environments.

task

1 Your first task is, in the same manner as Mini-Projects 1 and 2, is to identify a design problem related to this grand challenge. While the source of this problem could be technical, economic, social, and/or environmental, fully defining the problem will most likely require consideration of all of these aspects. This will take substantial research, dialogue, and thinking. This task will require a clear statement of the design problem, a comprehensive set of customer requirements, a set of engineering specifications that address the customer requirements, and a House of Quality $(\mathrm{HoQ})$ that relates the customer requirements to the engineering specifications. Major trends should be identified.

$2 \& 3$ Similar to Mini-Project 2, your second task is to generate a set of design alternatives for your design problem and the third task is to select the most promising design alternative.

4 The fourth task is to develop your most promising design alternative, using embodiment design tools and techniques. This will include developing CAD models of your system (or a similarly detailed plan if your system is a process). Evidence for consideration of assembly, materials, configuration, production, variation, reliability, optimization, tolerancing, and/or other embodiment design issues must be clear in the report. Other design activities such as prototyping and testing will be given additional consideration.

\section{resources}

Listed here are some starting points for your research. You should go well beyond these resources using your own research, experiences, and knowledge.

- Sahely, H.R., Kennedy, C.A., and Adams, B.J., 2005, "Developing Sustainability Criteria for Urban Infrastructure Systems," Canadian Journal of Civil Engineering, Vol. 32, pp. 72-85, doi: 10.1139/L04-072. (UBLearns)

- Panel on Urban Population Dynamics, Mark R. Montgomery, Richard Stren, Barney Cohen, and Holly E. Reed, Editors, 2003, "Cities Transformed: Executive Summary," National Research Council. (UBLearns)

- Allenby, B., 2008, "Complexity in Urban Systems: ICT and Transportation," IEEE International Symposium on Electronics and the Environment, 19-22 May. (UBLearns)

- Hansen, R.J., Magee, C., de Neufville, R., Robins, R. and Roos, D., 2006, "Research Agenda for an Integrated Approach to Infrastructure Planning, Design and Management," International Journal of Critical Infrastructures, Vol. 2, Nos. 2/3, pp. 146-159. (UBLearns)

- Correia Guedes, M., Pinheiro, M., Manuel Alves, L., 2009, "Sustainable Architecture and Urban Design in Portugal: An Overview," Renewable Energy, Vol. 34, pp. 1999-2006. (UBLearns)

\section{Mini-Project 3 Description}

